\title{
PHYSIO-CHEMICAL AND MECHANICAL DETERIORATION OF MONUMENTAL MUD BRICK IN EGYPT.
}

\author{
Abd El-Hady, M. ${ }^{1}$ \& Abd El Hafez, A. ${ }^{2}$ \\ 1Prof. Conservation dept., Faculty of Archaeology, Cairo Univ., Giza, Egypt \\ ${ }^{2}$ Asses. Lecture Conservation dept., Faculty of Archaeology, Cairo Univ., Giza, Egypt
}

E-mail: elhady_esna@yahoo.com

\begin{abstract}
Mud brick made from soil materials widely used in building the earthen buildings dating back to prehistoric times on wards. The ancient Egyptians had built those unique and historical buildings to be used as houses, tombs, castles and parts of temples because the raw materials used for producing mud-brick widely existing in the Nile valley and many other historical sites. The present research deals with illustrating the technology of manufacturing mud-brick and the inorganic and organic materials used in this technology. The results obtained by this research showed that the physio-chemical and mechanical properties of mud-brick greatly varied from site to another. A scientific survey carried out on different samples of mud-brick collected from the most deteriorated parts of some historical buildings showed that the physical structure of these samples seriously collapsed and the samples became fragile materials due to the severe effects of deterioration factors mainly atmospheric conditions, rain water, ground water, biological agents (termites and micro organisms ) ...etc.
\end{abstract}

Keywords: Mud brick, Tombs, Manufacturing, Rain water, Ground water.

\section{Introduction}

The earthen architecture is considered the oldest architecture in the world compared with stone architecture. In the ancient centers of civilizations man had used mud or soil materials mixed with organic and inorganic materials for manufacturing mud-brick which is considered the principal building material for constructing various buildings from the down history [1]. These buildings and their sites have come to be valued by many elements of society for variety of reasons: for scholars who would like to study the development of ancient building technology through the ages, for nations who are proud of either national or ethic identities and heritage and many countries exploit these unique sites successfully as source of foreign currency through their appeal for tourism which is considered the largest industry in the world. In recent decades these sites have come to be viewed as the common heritage of humanity which they should be accessible to visitors from around the world. It is essential to note that the Arabic world is the cradle of ancient civilizations that shaped our Arabic societies and if this wealthy heritage is deteriorated or destroyed the tangible evidence will be erased for future generations because the archaeological 
heritage can't be repeated or reinstated. The only way to ensure its survival is to devise and employ strategies of caring and preservation of historical buildings and heritage sites [2]. These sites must be rehabilitated, up graded and used carefully for as unique and non-repeated resources. In the recent decades the historical buildings built of mud-brick in the Arabic countries are threated by varied and complex deterioration factors which are reasonable on changing the

\section{Materials and Methods}

The geological and archaeological studies showed that mud brick blocks used for building the historical buildings consists of various inorganic and organic materials mainly clay minerals, sand, lime, aggregates and animals dung as well as chopped straw as binding or cementing materials. The most important groups of clay minerals are as follows:

1- Kandites group (Kaolinite, Nacrite, Decite and Halocite). 2- Illite group (Illite, glauconite, barammalite). 3Smectite group (Montmorillinite, Saponite, and Hectorite). 4- Playgorskite group (Attapulgite) [4]. The scientific studies proved that mud brick which

\section{Results}

\subsection{XRD Analysis}

Different samples of mud brick taken from the historical Aswan Necropolis locating south Egypt, fig . $(1-a, b)$. These samples have been

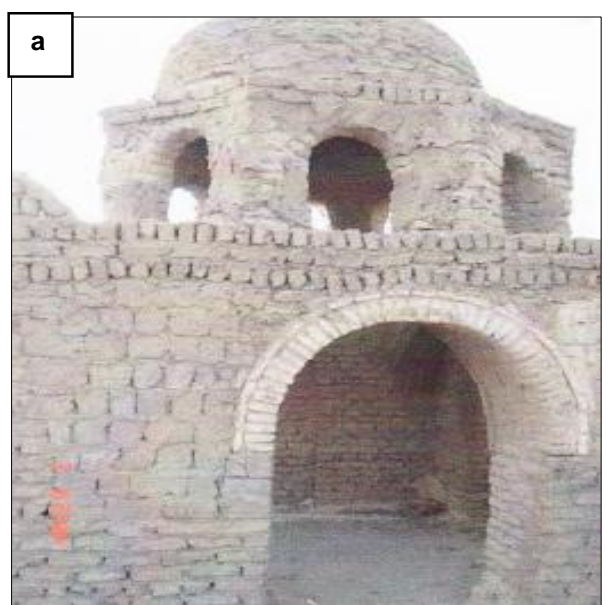

building materials of these historical buildings into un cohesive materials [3]. Among of these factors are the severe actions of atmospheric conditions, rain water, air pollution, ground water, microorganisms, earthquakes, neglectance , rapidly increase of urbanization and lack of financial resources used for their restoration and conservation. It was observed in the last few years that the growth of mass tourism cause serious damage to the archaeological sites.

contains high percent of Montmorillonite will absorb more water than mud brick of less percent of Kaolinite these minerals will expose to swelling when mud brick blocks attacked by different sources of moisture. Various mud brick samples have been collected from some historical buildings locating in different archaeological sites in Egypt in order to know their principal mineral constituents and the types of organic materials present in these samples. These samples have been analyzed and investigated by XRD, Polarizing microscope (PLM), Scanning electron microscope (SEM) equipped with EDX. analyzed by XRD. The obtained results showed that Kaolinite, Quartz, Calcite Gypsum, Halite are the main components, as shown in fig $(2-a, b)$.

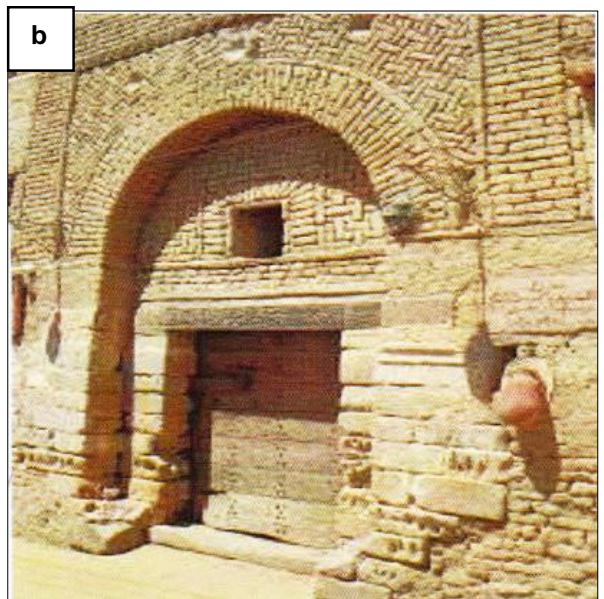

Figure (1) Adobe tomb a from Aswan Necropolis b an Islamic house from Kharga Oasis 


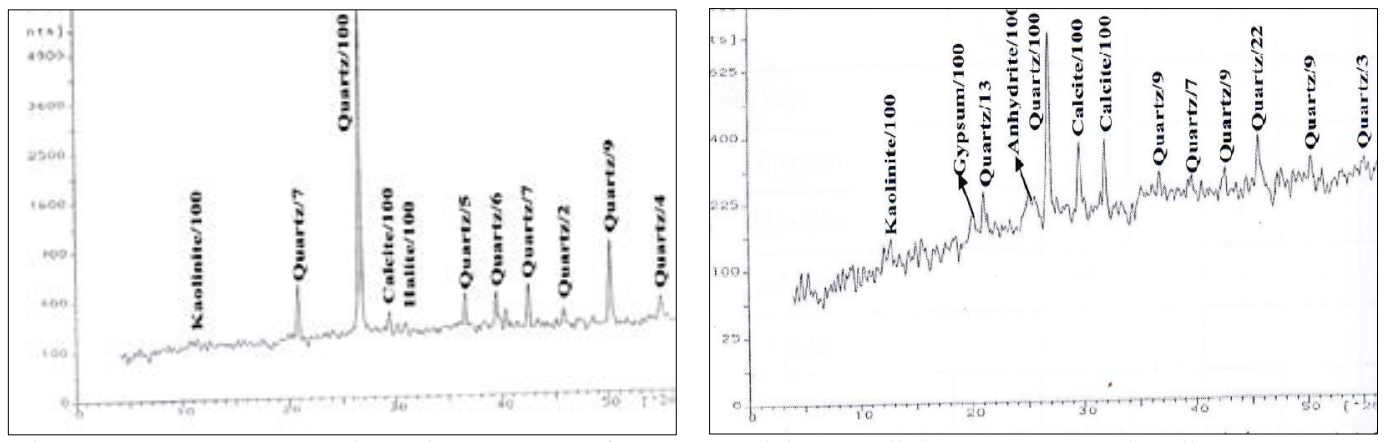

Figure (2) XRD patterns show the presence of Quartz, Calcite, Kaolinite, Gypsum and Halite.

\subsection{Polarizing Microscope investigations}

The previous samples have been investigated by PLM and the obtained results showed that these principal mineral presenting in the samples of Aswan Necropolis are Quartz, Calcite, Hydrated iron oxides, fig (3-a) where as the principal minerals of Kharga oasis Islamic buildings sample are Quartz, Mica, Plagiclase, fig (3-b). The obtained results showed that the mineral constituents of mud brick used in the previous historical buildings varied greatly due to the variable soil materials used in manufacturing this mud brick. In addition to the minerals previously mentioned PLM investigation showed the presence of fragments of ceramic and stones which where added to the mixtures of mud during the manufacture of mud brick to increase the mechanical properties of the blocks used for constructing the historical adobe buildings, fig (3-c).
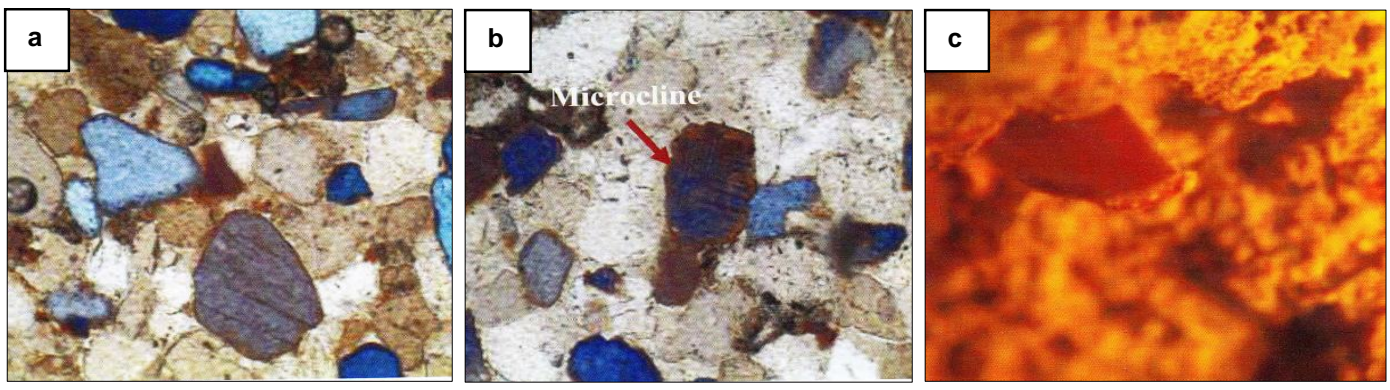

Figure (3) PLM investigation a quartz, Calcite and Hydrated iron oxides, b Quartz, Mica, Plagioclase and Microcline, c ceramic shred presenting in the sample.

\subsection{SEM equipped with EDS}

The results obtained by EDS showed that the samples contain different mineralogical elements such as $\mathrm{Si}, \mathrm{Al}$, $\mathrm{Ca}$, $\mathrm{Fe}$ and $\mathrm{Cl}$, fig (4). SEM electro micrographs illustrated the presence of Quartz, Kaolinite, Halite, fig (5-a). As well as the presence of chopped straw wooden fragments which were added to the mixture of mud as binding materials, fig (5-b \& c). It is important to recognize that the pernicious effects of atmospheric conditions mainly continuous variations of air temperature and relative humidity as well as wind erosion [5] in the surrounding lead to physical and chemical deterioration to the physical structure and mineral constituents of mud brick. [6]. The most cited factors of deterioration are moisture sources (ground water, rain water, and condensation) play an active role in swelling of clay minerals presenting in mud brick because they are considered hygroscopic minerals [7]. The penetrated water into mud brick will cause recrystallization of salts leading to serious disruption of mud brick structure and the disintegration of its mineral constituents, fig (5-d). Microorganisms such as fungi and lichen species play a 
dominant role as biogeochemical and biogeophysical factors causing the degradation of the organic materials (animal dung and chopped straw) used in mud brick production as binding materials fig (5-e). The obtained results showed that Pencillium, Asperagillus flavus are the most common species of fungi presenting in mud brick in Egypt. These microorganisms can also cause harmful damage to the mineral constituents of mud brick physically and chemically where they cause desegregation to these minerals and also they can produce several kinds of acids such as oxalic acid which plays and active in leaching of some minerals like mica. When this acid attacks Calcium Carbonate presenting in mud brick, Calcium oxalate will be resulted. White termite are considered very serious insects which cause severe damage to the historical adobe buildings because they prefer to eat the botanical binding materials that present in this adobe leaving deep grooves and transforming this adobe into fragile building material this symptom is widely noticed in many adobe historical buildings in upper Egypt partially in dried areas.

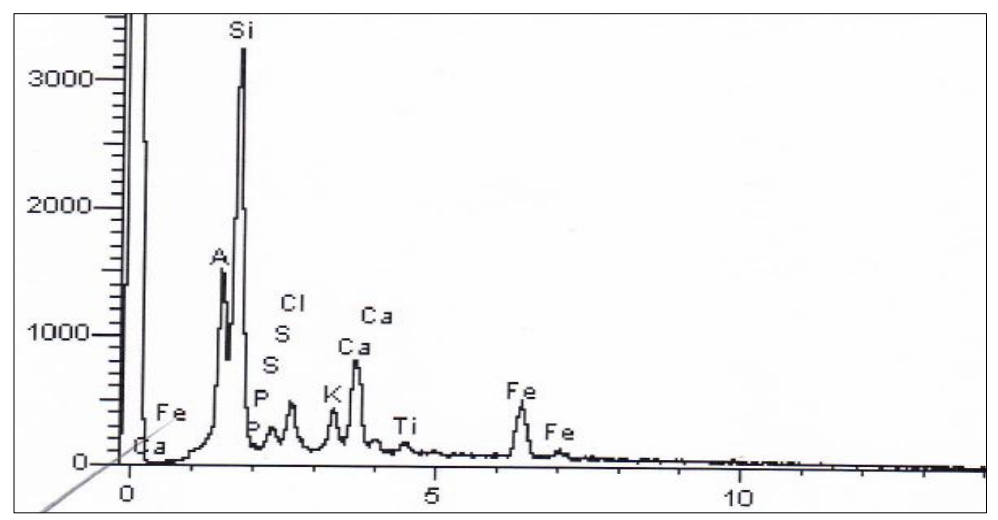

Figure (4) EDS pattern shows different mineralogical elements such as $\mathrm{Si}, \mathrm{Al}, \mathrm{Ca}, \mathrm{Fe} \& \mathrm{Cl}$
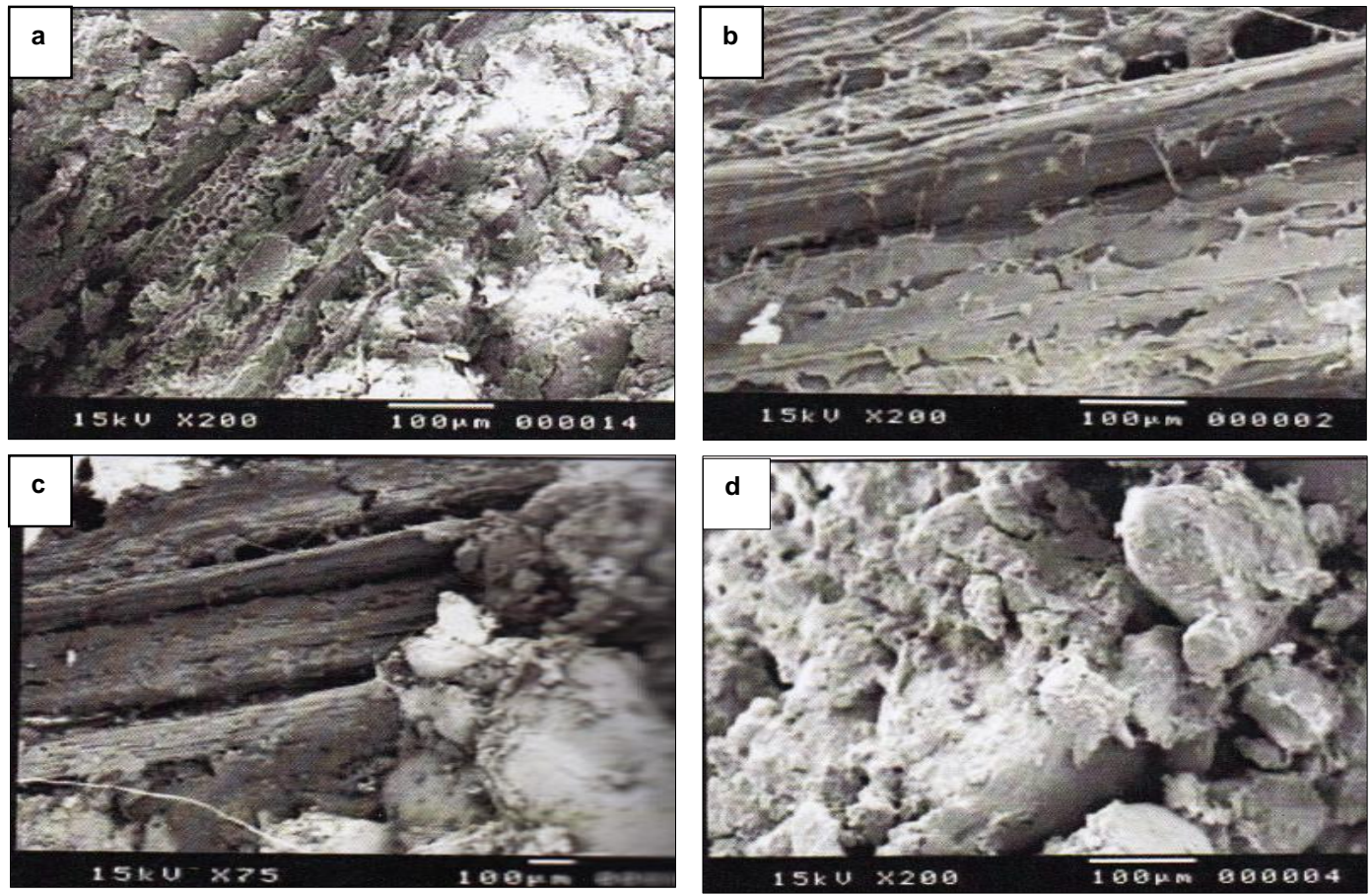

Figure (5) SEM photomicrograph shows $\underline{\mathbf{a}}$ the presence of Quartz, Kaolinite, $\underline{\mathbf{b}}$ presence of chopped straw and wooden fragments as binding materials in the samples, $\underline{\mathbf{c}}$ collapse of physical structure of mud brick, $\underline{\mathbf{d}}$ fungal growth inside the mud brick sample. 


\section{Conclusion}

In conclusion and based on this scientific study, the adobe historical buildings in the Arabic world show great development achieved by the Arabic builders through the ages with its historical , architectural and artistic values. These adobe buildings were constructed to interact with the climatic conditions because the soil materials used in constructing these buildings are characteristics with its high thermal capacity and low thermal conductivity. This type of building materials can moderate extreme outdoor atmospheric conditions and save suitable internal environment for the inhabitants of these buildings. By means of the combined use of different analytical techniques carried out on various adobe samples collected from some historical buildings in Egypt. The results have indicated that the micro and chemical structure of adobe blocks lost its cohesion due to several deterioration factors as previously mentioned in the text. The SEM images and EDS spectra showed that the mineral constituents of adobe seriously disintegrated and big amount of organic binding materials (chopped straw) severely deteriorated.

\section{References}

[1] El-Gohary, M., (2012). The contrivance of a new mud bricks for restoring and preserving the Edfa ancient granary-Sohag, Egypt, IGCS, Vol. 3 (2), pp: 67-78

[2] Staurt, B., (2007). Analytical techniques in materials conservation, John Wiley, England.

[3] El-Gohary, M., (2012). Behavior of treated and un-treated lime mortar before and after artificial weathering, Int. Restoration of Buildings and Monuments, Vol. 18 (6), pp: $369-380$

[4] Warren, J. (1999)., Conservation of earth structure, Butterworth Heimann.

[5] Homes, J. (2003)., Wind loading of structure, Spon press, London.

[6] Agnew, N., Preusser, F. \& Druzik, J., (1987). Strategies for adobe preservation, Getty conservation institute, research program, Rome, ICCROM, pp: 1-13

[7] Pecker, A., (2007). Soil behavior under cyclic loading, Springer, Berlin. 